\title{
Research on the Adjustment Strategy of Major Identity of Higher Vocational Students
}

\author{
Xiaohua Shi \\ Hainan Institute of Science and Technology, Hankou, Hainan, 571126
}

Keywords: Adjustment Strategy, Higher Vocational Students, Major Identity

\begin{abstract}
This paper analyzes the connotation and constituent elements of Major Identity systematically, divides the composition of Major Identity into professional external recognition and professional internal recognition, and analyzes the relationship between the two parts. The study shows that professional education and individual professional interest will have a significant direct impact on professional internal recognition, and social recognition and employment prospects have a significant indirect effect on professional internal recognition. Professional external recognition is to improve the overall level of professional recognition of the entry point, Major Identity through the Major Identity of the identity shown. Therefore, to strengthen the Major Identity of vocational students should be professional external recognition as the focus, the specific recommendations include strengthening the professional ideological education, cultivate professional adaptability; deepen the integration of industry and education, improve professional education; to help students in accordance with the rational choice of interest, professional study.
\end{abstract}

\section{Introduction}

The word "identity" was first proposed by the famous Austrian psychoanalyst Sigmund Freud. He agrees as a psychological convergence process of the individual's value, norm, and appearance to another person or group (Goodson, I.F. \& Cole, A.L. 1994).

Whether it is from the perspective of self-identity or social identity, the "Major Identity" of college students is a dynamic recognition process of knowledge, skills and values involved in the profession. This process includes understanding, acceptance, love and even action. Learn "professional", after graduation based on "professional" choice "occupation" and the occupation as a personal lifelong development goals.

Therefore, in this study, "Major Identity" refers to the vocational students in the past experience on the basis of the professional (and even the future correspondence) awareness and acceptance of the psychological process, specifically as follows: by the professional The understanding and understanding, willing to take a positive attitude and active behavior to learn and explore, so as to achieve the professional (and even the corresponding occupation) acceptance and recognition.

\section{Research Methods}

Taking the students of three vocational colleges in Hainan Province as the research object, 450 questionnaires were distributed, and the questionnaires were removed and the questionnaires were deleted. (21.5\%), sophomore 102 (25.8\%), junior 149 (37.7), liberal arts class 83 (21\%), male (female) (64.6\%), art class 57 (14.4\%); voluntary selection of 283 people (71.6\%), according to their parents or others willing to choose volunteer 112 (28.4\%).

(1) professional external recognition scale with reference to Mao Yongxing prepared by the impact of Major Identity factor survey scale, on the basis of this revised. The survey is divided into three dimensions: professional social recognition and employment prospects, professional interests, professional education, a total of 16 items, with 5 points, 1 on behalf of "very small", 5 on behalf of "great", the higher the score The stronger the impact of this factor on Major Identity. The internal consistency coefficient of professional social recognition and employment prospect, professional 
interest and professional education were $0.87,0.85$ and 0.86 respectively, and the internal consistency coefficient of the total scale was 0.93 . The confirmatory factor analysis showed that the model was well fitted, $\chi 2 / \mathrm{df}=2.29$, $\mathrm{RMSEA}=0.06$, $\mathrm{RMR}=0.03$, GFI $=0.93$, CFI $=0.96$.

(2) Professional internal recognition scale with reference to the Southwest University Qin Panbo (2009) prepared by the Major Identity scale revised. The scale is divided into four dimensions: professional cognition, professional emotion, professional behavior and appropriateness. A total of 15 items are used. The score is 5 points, 1 stands for "totally nonconformity" and 5 is "perfect". The internal consistency coefficients of each dimension were $0.80,0.82,0.80$ and 0.79 , respectively, and the internal consistency coefficient of the total scale was 0.90. The confirmatory factor analysis showed that the model was well fitted, $\chi^{2} / \mathrm{df}=2.66, \mathrm{RMSEA}=0.07, \mathrm{RMR}=0.05, \mathrm{GFI}=0.93$, $\mathrm{CFI}=0.94$.

\section{To Improve the Major Identity of Vocational Students Strategy}

From the above analysis, we can see that there are relationships between different parts of Major Identity, professional external recognition can promote professional internal identity, and professional recognition of the overall level of how, and ultimately through the professional internal recognition level, professional external recognition is to improve professional Identify the overall level of entry. Therefore, to strengthen the Major Identity of vocational students, should be professional external recognition as the focus, through the role of professional recognition and employment prospects, personal professional interests, professional education three factors to promote the Major Identity of vocational students improve. Based on this study, the following recommendations are made:

According to the results of the study, professional social recognition and employment prospects will have a significant positive and negative impact on students' professional internal identity. Students are more likely to have a relatively comprehensive and objective assessment of the professional development of different areas, professional prestige, employment, respect and so on, and will have a relatively comprehensive and objective evaluation of the profession, and then produce professional emotions to promote learning behavior happened. A comprehensive understanding of the profession depends on the following two aspects:

Professional and employment there is a close connection, only to learn professional to get the key employment capacity. Vocational colleges to cultivate talents to employment-oriented, through the implementation of professional education to the community to achieve their own services to the economic and social functions; at the same time vocational colleges with educational functions, to help students develop the correct professional values is its educational function Of a manifestation. Through the implementation of ideological education of students, establish the correct professional values, help students dig out the professional activities given to people beyond the material to enjoy the spirit of satisfaction, to achieve personal values and social values of unity. Good professional values determine the individual's career choice and development, but also affect the individual's work attitude, behavior and performance. Vocational students in the pre-job preparation phase, the same by the impact of professional values, determine their learning attitude, learning behavior and learning outcomes.

Professional thinking refers to the students of their own professional, subject knowledge, understanding and attitude. The scope of professional education does not only include the profession itself, but also to the academic and even extended to the future employment and occupation, is the starting point of professional education and teaching. Higher vocational colleges to students of professional ideological education, is the community of professional and technical needs of the talent requirements of the system into a professional understanding of students, feelings and the pursuit of the way is to learn and improve their studies, employment Link up the channel. As a student, if the lack of a comprehensive understanding of their own professional, understanding, it is impossible to truly understand their own professional, it is impossible to form the correct professional awareness and professional emotions, resulting in learning interest and motivation. The content of professional ideological education should include the introduction of 
professional introduction at the beginning of the course, so that students learn what, how to learn, correct professional attitude; throughout the vocational education throughout the career planning classes to guide students to determine their own career goals, to understand their own And find out the gap, determine the direction of efforts to cultivate positive motivation to learn; pre-graduation employment guidance classes to help students establish the correct employment concept, learn skills skills, enhance job confidence and improve employability.

\section{Deepen the Integration o Production and Education}

The results of this study found that professional education has a positive impact on professional internal recognition. Professional education is the connection between social needs and personnel training. Only through the implementation of professional education can we achieve the dual goal of serving social development and realizing human development. Therefore, we from the professional settings, curriculum adjustment, training model and learning atmosphere four aspects of recommendations to promote vocational students Major Identity.

Higher vocational colleges are the main body of the implementation of professional education. The establishment of professional and professional groups is the basic project of the construction of higher vocational colleges. It is related to the survival and development of schools and the relationship and direction of personnel training. At present, there are many problems in the construction of professional colleges and universities, such as professional and professional groups set up social research is not sufficient; lagging behind the economic and social development; blind innovation, seeking hot, seeking more, seeking the whole, and ultimately not only cause waste of educational resources, But also appeared in the recruitment difficult, more difficult employment phenomenon. Therefore, vocational colleges should attach importance to and strengthen the construction of professional and professional groups, and meet with the needs of regional industries, advancing with the times, around the service industry or the location of the region, geographical, industry and other advantages in their own Based on the school set up professional, the development of professional groups.

The current higher vocational education to cultivate high-quality technical skills application talents for the first line of production, construction, management and service, which is the basic goal of personnel training in higher vocational colleges. (2015) argues that the training objectives are ambiguous. It points out that the main factors influencing the training objectives of higher vocational talents include national policy, socioeconomic form and industrial structure, occupational classification and vocational skills standards and individual development needs of students. At present, the training of "high-quality technical and technical personnel" of the specifications to a certain extent, in line with the country, socio-economic and industrial structure requirements, but the occupational classification and standards and student development needs to be considered inadequate. Therefore, need to be further adjusted in order to better adapt to social needs and the growth of higher vocational students needs. (2016) put forward the concept of "classifying and cultivating diversified talents", and established the "basic + promotion" type of higher vocational education classification talent training target model, pointed out that in the cultivation of high-quality technical skills on the basis of the basic specifications, Vocational colleges can cultivate the "technician type, complex type, entrepreneurial type, ascension type, internationalization" and other types of upgrading, and build "platform + module" curriculum structure with the matching, the formation of general education platform, professional group Platform, post group platform, job orientation module, professional elective course or classification training module elective course group and general election elective course system, the different types of different needs of students to develop corresponding training programs. 


\section{Conclusion}

This study found that individual professional interests have a significant positive impact on students' professional internal identity. Admittedly, interest is driving within the drive, is to promote the formation of Major Identity of the intrinsic motivation. Vocational students to carry out professional learning, the role of internal power can not be overlooked. Vocational colleges should be in the professional information publicity, professional choice system and personalized career planning efforts, as far as possible respect for the professional interests of students to promote their choice of professional, professional learning.

\section{Acknowledgements}

Fund Project. Hainan Provincial Education Science "13th Five-Year Plan" 2016 annual key issues: "Hainan Province, vocational students professional recognition of the impact of learning investment", Project No.: QJZ13516006

\section{References}

[1] Goodson, I.F. \& Cole, A.L. (1994). Exploring the Teacher's professional Knowledge: Constructing Identity and Community. Teacher Education Quarterly, 21 (1): 85-105.

[2] Duan Zhiping, Wang Shengjia, Shusheng (2015). On the modern vocational education system under the higher vocational education personnel training objectives. China vocational and technical education, 15.

[3] Fan Mingcheng (2013). China's college students choose the professional influencing factors. Modern education management, 1: 113-117.

[4] Organs, Fan Mingcheng (2014). Analysis of the Factors Affecting the Teaching Quality of Higher Vocational Colleges. Chinese Vocational and Technical Education, 26.

[5] Gao Lei (2013). Investigation and study on the Major Identity of students in Y vocational college in Shanxi province.

[6] On the Causes and Countermeasures of "Dislocation of Employment" in Higher Vocational College Students from the Perspective of Professional Setup. Education Exploration, 7: 151-152.

[7] Mao Yongxing (2011). The Major Identity of teachers and students and their relationship with career decision-making difficulties. Chongqing: Chongqing Normal University.

[8] The Construction and Implementation of the Curriculum System of Higher Vocational Education Based on Classification and Training. China Vocational and Technical Education, 11.

[9] Qin Panbo (2009). Characteristics of college students' Major Identity and its related research. Chongqing: Southwest University.

[10]Modern Apprenticeship: A New Paradigm for Cultivating Highly Skilled Talents. Research on Higher Education in China.

[11]Wu Minglong (2009). Structural Equation Model. Chongqing: Chongqing University Press.

[12]Xu Lin, Tang Chen, Qian Jing, Qin Hu, Meng Hui (2011). The Relationship between Professional Interest and Professional Tendency and Behavior of College Students. Psychological Research, 4: 72-76.

[13]Zong Xiaowu (2012). The influencing factors of professional choice of college students and their relationship with professional satisfaction. Jiangsu Science and Technology Information, 12: 25-26. 